\title{
Neuronal ceroid-lipofuscinosis: preferential metabolic alterations in thalamus and posterior association cortex demonstrated by PET
}

\author{
A G De Volder, S Cirelli, Th de Barsy, J M Brucher, A Bol, Ch Michel, A M Goffinet
}

\begin{abstract}
Regional brain glucose utilisation was investigated with positron emission tomography (PET) and fluorodeoxyglucose (FDG) in four siblings with neuronal ceroid-lipofuscinosis. A consistent pattern was found, namely a decrease of glucose utilisation in all grey structures but more marked at the level of the thalamus and posterior association cortex. The severity of metabolic anomalies was correlated with the degree of clinical impairment and with disease duration; they were the most severe in the oldest patient, who was also the most affected clinically, intermediate in two others, and minimal in the subject with the shortest period of development of the disease. These observations suggest that PET is useful for the definition of anatomical targets of metabolic diseases and for the investigation of their pathophysiology.
\end{abstract}

Neuronal ceroid-lipofuscinosis (NCL) is a clinically heterogeneous group of inherited neurodegenerative diseases characterised by intellectual deterioration, psychiatric disturbances, seizures, movement disorders, visual loss and spasticity. ${ }^{1}$ Based on the age at onset, NCL is divided into four subgroups: infantile ("Santavuori, Haltia"), late infantile ("Jansky, Bielschowsky"), juvenile ("Batten, Mayou, Spielmeyer, Vogt, Sjögren"), and adult ("Kufs") types. The diagnosis of NCL is usually ascertained by muscle, nerve, skin, or conjunctival biopsies, ${ }^{2}$ which reveal accumulation of an autofluorescent lipopigment (lipofuscin) within cytosomes. The biochemical nature of lipofuscin and the presumed enzyme deficit in NCL are unknown and, despite various hypothese ${ }^{23}$ there are no satisfactory explanations for the accumulation of lipopigment in neural cells nor for the wide variety of neurological symptoms in this disease.

In an attempt to gain insight into the pathophysiology of the disorder, we studied regional brain glucose metabolism in four siblings with histologically-proved neuronal ceroid lipofuscinosis. As glucose, with oxygen, is the main substrate of the brain at all ages, regional brain glucose utilisation provides an index of local neural function. Studies of regional brain metabolism should thus allow the determination of the main neuroanatomical targets of the disease and their correlation with clinical symptoms.

\section{Materials and methods \\ Patients}

The four cases were all affected siblings from a family of 11 children: case 1 was a woman aged 35 years who had been affected for 26 years; case 2 was a 31 year old female with 22 years of disease; case 3 a man aged 26 years in whom the disease has evolved for 17 years and case 4 a 28 years old female with a slow development of the disease for at least 12 years. Their clinical history has been described previously. ${ }^{45}$ In all four patients, learning difficulties (minimal for subject 4) were observed from about the age of 9 years, followed by bradykinesia and stiffness of the limbs which initially responded favourably to levodopa (table 1). Subsequently gait disturbances, dysarthria, and clumsiness worsened progressively.

At the time of the PET studies, they showed similar symptoms, with various degrees of impairment related to disease duration. The cardinal features were a florid, akinetorigid Parkinsonism associated with intellectual impairment, motor incoordination, spasticity, slow eye movements, and peripheral neuropathy. In addition, patient 1 , the oldest and most affected, exhibited myoclonic jerks, seizures, and urinary incontinence. MRI and CT scans showed discrete and diffuse cortical atrophy in patients, 1, 2 and 3 , and a cerebellar atrophy in the oldest subject (case 1). Light microscopic examination of blood samples disclosed vacuolated lymphocytes in the four cases. Nerve and muscle biopsies were studied in the oldest patient by light and electron microscopy and revealed alterations typical of NCL, particularly the presence of cytoplasmic PAS positive, autofluorescent lipopigments, ${ }^{1}$ and fingerprint-like profiles. Neuropsychological studies of higher brain function could not be performed due to the patient's inability to cooperate.

Patients were compared with 39 neurologically normal volunteers, mean (SD) age, 25.6 (7.7 years). All subjects or their parents gave their informed consent before the PET study, the protocol of which had been approved by the Medical Ethics Committee of the University of Louvain. A summary of clinical data is provided in table 1 . 
Table 1 Summary of the main clinical features of the four siblings with neuronal ceroid-lipofuscinosis

\begin{tabular}{|c|c|c|c|c|}
\hline Patients & 1 & 2 & 3 & 4 \\
\hline $\begin{array}{l}\text { Sex/Age } \\
\text { Duration of illness }\end{array}$ & $\begin{array}{l}\text { Female } 35 \\
26 \text { years }\end{array}$ & $\begin{array}{l}\text { Female } 31 \\
22 \text { years }\end{array}$ & $\begin{array}{l}\text { Male } 26 \\
17 \text { years }\end{array}$ & $\begin{array}{l}\text { Female } 28 \\
12 \text { years }\end{array}$ \\
\hline $\begin{array}{l}\text { First description of symptoms: }{ }^{\star} \\
\text { Stiffness of the limbs } \\
\text { Akinesia } \\
\text { Rest tremor } \\
\text { Parkinsonian face } \\
\text { Dysarthria/Dysphagia } \\
\text { Incoordinated movements } \\
\text { Behavioural troubles } \\
\text { Intellectual impairment } \\
\text { Response to levodopa }\end{array}$ & $\begin{array}{l}13 \text { years } \\
+++ \\
+++ \\
++ \\
++ \\
++ \\
+ \\
++ \\
++ \\
+++\end{array}$ & $\begin{array}{l}14 \text { years } \\
+++ \\
++ \\
+ \\
++ \\
+ \\
+ \\
+ \\
++\end{array}$ & $\begin{array}{l}13 \text { years } \\
+ \\
+++ \\
+ \\
++ \\
++ \\
+ \\
+ \\
+ \\
++\end{array}$ & $\begin{array}{l}16 \text { years } \\
+ \\
++ \\
\text { NA } \\
+ \\
+ \\
+ \\
+ \\
+ \\
+\end{array}$ \\
\hline \multicolumn{5}{|c|}{ Neurological symptoms at the time of PET. } \\
\hline Gait disturbances & Bedridden & Wheel-chair & With aid & With aid \\
\hline $\begin{array}{l}\text { Bradykinesia } \\
\text { Stiffness }\end{array}$ & ++ & $\begin{array}{l}++ \\
+++\end{array}$ & $\begin{array}{l}++ \\
+\end{array}$ & $\begin{array}{l}+ \\
+\end{array}$ \\
\hline Rest tremor & + & - & - & - \\
\hline Dysarthria & ++ & +++ & ++ & + \\
\hline Dysaphagia & +++ & ++ & ++ & + \\
\hline Dystonic movements/dyskinesias & ++ & - & +++ & - \\
\hline $\begin{array}{l}\text { Spasticity/Pyramidal features } \\
\text { Seizures }\end{array}$ & $\begin{array}{l}+++ \\
++\end{array}$ & \pm++ & \pm++ & $\pm^{++}$ \\
\hline Myoclonic jerks & ++ & - & - & - \\
\hline Visual impairment & - & - & - & - \\
\hline Intellectual impairment & +++ & $+1++$ & ++ & + \\
\hline \multicolumn{5}{|l|}{ Treatment (dose per day) } \\
\hline $\begin{array}{l}\text { Levodopa (mg/day) } \\
\text { Other }\end{array}$ & $\begin{array}{l}300 \mathrm{mg} \\
\text { Baclofen }\end{array}$ & $\begin{array}{l}400 \mathrm{mg} \\
\text { Antichol }\end{array}$ & $\begin{array}{l}125 \mathrm{mg} \\
\text { Antichol }\end{array}$ & $230 \mathrm{mg}$ \\
\hline
\end{tabular}

$\star$ data according to ${ }^{4}-=$ absent; $+=$ mild; $++=$ moderate; $+++=$ severe; $N A=$ non available; Antichol = anticholinergics, trihexyphenidyl hydrochloride (Artane ${ }^{\mathfrak{k}}$ ).

Positron emission tomography: data collection and analysis

Cerebral glucose metabolism was measured using an ECAT III one-ring tomograph and the fluorodeoxyglucose (FDG) autoradiographic method, following a protocol described previously. ${ }^{6}$ Briefly, subjects (drug-free and fasted for at least 24 hours before the study) were studied at rest, with eyes closed and ears uncovered. Beginning 30 to $45 \mathrm{~min}$ utes after FDG injection, eight brain levels were studied sequentially, in the canthomeatal orientation. Images had a thickness of $15 \mathrm{~mm}$ FWHM and were reconstructed at an in-plane resolution of $9 \mathrm{~mm}$ FWHM; attenuation correction was carried out with a contour-finding algorithm and a uniform attenuation coefficient of 0.08 . Irregular regions of interest $\left(\right.$ ROIs) ${ }^{78}$ were defined under visual control by following isocontours on the colour-coded images, with reference to common neuroanatomical hallmarks, to CT or MRI scans, to a neuroanatomical atlas ${ }^{9}$ and to a series of normal anatomical brain slices prepared in the same canthomeatal orientation. Due to the limited precision in ROI definition, only welldefined areas were considered for analysis (see table 2). To decrease the effects of variations in mean grey glucose utilisation, "relative" metabolic rates were expressed in percentage of a "mean grey metabolic value" defined by drawing large regions of interest encompassing most of the grey matter in the PET slice at the level of the basal ganglia. Metabolic data were not corrected for cerebral atrophy. Although some discrete atrophy was present, it affected all cortical areas similarly and was not predominant in any particular region of the brain.

Absolute and relative glucose utilisation rates in the four patients were compared to those in normal volunteers by using the following procedures: 1) ANOVA with a repeated measures design for ROI values ${ }^{8}$ and one grouping factor for pathological state (lipofuscinosis or normal); 2) Posthoc pairwise comparisons of a few selected ROIs using $t$ tests with the Bonferroni correction for multiple comparisons. In addition, the four patients were also compared individually with the control sample by using as a criterion for anomaly a deviation by more than 2 SD from the control values (table 2 ).

\section{Results}

Absolute and relative glucose utilisation rates, estimated in various brain anatomic divisions in the four patients and in control subjects are shown in table 2. Glucose utilisation, measured over large areas of grey matter, averaged (SD) $36.3(4.9) \mu \mathrm{mols} /(100 \mathrm{~g} \mathrm{~min})$ in patients versus $51.2(7.6) \mu \mathrm{mols} /(100 \mathrm{~g} \mathrm{~min})$ in control subjects. Absolute metabolic rates were significantly decreased $(p<0.05$, Bonferroni correction) in all grey structures considered. Relative metabolic rates (calculated in order to minimise the effect of variations in mean grey glucose utilisation) were significantly decreased at the level of the thalamus only (comparison of 8 ROIs at an overall significance level of 0.05). By contrast, the striatum and cerebellum appeared relatively more preserved than other regions.

When NCL patients were compared individually with control subjects, hypometabolism ( $>2$ SD) was demonstrated in all brain regions of the oldest patient (subject 1 ) but was

Table 2 Absolute and relative metabolic rates in the four patients and control subjects. Absolute values are expressed in $\mu$ mols/100 $g$ min; relative values in $\%$ of mean grey metabolism; ${ }^{\star}=$ deviation from control values by more than $2 S D$

\begin{tabular}{|c|c|c|c|c|c|c|c|c|c|}
\hline Patients & Frontal cx & Temporal cx & Par-Occ cx & Visual cx & Fr-mesial cx & Striatum & Thalamus & Cerebellum & Mean grey \\
\hline $\begin{array}{l}\text { Absolute values } \\
\text { Subject } 1 \\
\text { Subject } 2 \\
\text { Subject } 3 \\
\text { Subject } 4 \\
\text { Mean (SD) }\end{array}$ & $\begin{array}{l}31 \cdot 2^{\star} \\
39 \cdot 7 \\
39 \cdot 5 \\
41 \cdot 5 \\
38 \cdot 0(4 \cdot 6)\end{array}$ & $\begin{array}{l}31 \cdot 0^{\star} \\
36 \cdot 3 \\
38 \cdot 6 \\
39 \cdot 7 \\
36 \cdot 4(3 \cdot 9)\end{array}$ & $\begin{array}{l}26 \cdot 6^{\star} \\
33 \cdot 1^{\star} \\
37 \cdot 4 \\
37 \cdot 2 \\
33 \cdot 6(5 \cdot 1)\end{array}$ & $\begin{array}{l}26 \cdot 8^{\star} \\
36 \cdot 4 \\
41 \cdot 9 \\
43 \cdot 3 \\
37 \cdot 1(7 \cdot 5)\end{array}$ & $\begin{array}{l}31 \cdot 8^{\star} \\
36 \cdot 8 \\
38 \cdot 8 \\
41 \cdot 1 \\
37 \cdot 1(4 \cdot 0)\end{array}$ & $\begin{array}{l}32.9 \star \\
38.5 \\
41 \cdot 3 \\
39 \cdot 5 \\
38 \cdot 0(3 \cdot 6)\end{array}$ & $\begin{array}{l}22 \cdot 6^{\star} \\
29 \cdot 1^{\star} \\
31 \cdot 7^{\star} \\
34 \cdot 4 \\
29 \cdot 5(5 \cdot 0)\end{array}$ & $\begin{array}{l}25 \cdot 8^{\star} \\
33 \cdot 5 \\
33 \cdot 8 \\
33 \cdot 1 \\
31 \cdot 5(3 \cdot 9)\end{array}$ & $\begin{array}{l}29 \cdot 3^{\star} \\
36 \cdot 2 \\
39 \cdot 4 \\
40 \cdot 2 \\
36 \cdot 3(4 \cdot 9)\end{array}$ \\
\hline $\begin{array}{l}\text { Controls }(\mathrm{n}=39) \\
\text { Mean }(\mathrm{SD})\end{array}$ & $56 \cdot 0(8 \cdot 7)$ & $50 \cdot 1(7 \cdot 5)$ & $48 \cdot 3(7 \cdot 5)$ & $51 \cdot 7(8 \cdot 2)$ & $53 \cdot 1(8 \cdot 5)$ & $50.9(7 \cdot 8)$ & $46 \cdot 1(6 \cdot 6)$ & $42 \cdot 9(7 \cdot 2)$ & $51 \cdot 2(7 \cdot 6)$ \\
\hline $\begin{array}{l}\text { Relative values } \\
\text { Subject } 1 \\
\text { Subject } 2 \\
\text { Subject } 3 \\
\text { Subject 4 } \\
\text { Mean (SD) }\end{array}$ & $\begin{array}{l}106 \cdot 3 \\
109 \cdot 9 \\
100 \cdot 4 \\
103 \cdot 2 \\
104 \cdot 9(4 \cdot 1)\end{array}$ & $\begin{array}{c}105 \cdot 7 \\
100 \cdot 2 \\
98 \cdot 1 \\
98 \cdot 8 \\
100 \cdot 7(3 \cdot 4)\end{array}$ & $\begin{array}{l}90 \cdot 7 \\
91 \cdot 4 \\
95 \cdot 1 \\
92 \cdot 5 \\
92 \cdot 4(1 \cdot 9)\end{array}$ & $\begin{array}{l}91.2 \\
100.8 \\
106.5 \\
107.7 \\
101.5(7.5)\end{array}$ & $\begin{array}{l}108 \cdot 3 \\
101 \cdot 8 \\
98 \cdot 6 \\
102 \cdot 2 \\
102 \cdot 7(4 \cdot 0)\end{array}$ & $\begin{array}{c}112 \cdot 2 \\
106 \cdot 4 \\
104 \cdot 8 \\
98 \cdot 2 \\
105 \cdot 4(5 \cdot 8)\end{array}$ & $\begin{array}{l}77 \cdot 1^{\star} \\
80.5 \\
80.5 \\
85 \cdot 5 \\
80.9(3 \cdot 5)\end{array}$ & $\begin{array}{l}87 \cdot 8 \\
92 \cdot 5 \\
85 \cdot 9 \\
82 \cdot 4 \\
87 \cdot 1(4 \cdot 2)\end{array}$ & $\begin{array}{l}E \\
\bar{z}\end{array}$ \\
\hline $\begin{array}{l}\text { Controls }(\mathbf{n}=39) \\
\text { Mean }(\mathrm{SD})\end{array}$ & $109 \cdot 4(4 \cdot 8)$ & $98.0(3.5)$ & $94 \cdot 4(3 \cdot 8)$ & $101 \cdot 1(7 \cdot 1)$ & $103 \cdot 6(4 \cdot 3)$ & $99.5(4 \cdot 0)$ & $90 \cdot 3(5 \cdot 4)$ & $83.9(7.9)$ & - \\
\hline
\end{tabular}


Figure Images of cerebral glucose metabolism at the level of basal ganglia in the four siblings ( $A$ : subject 1; $B$ : subject $2 ; C$ : subject 3 ; $D$ : subject 4 numbered by order of disease duration). Glucose metabolic values (expressed in $\mu$ mols/ $100 \mathrm{~g} \mathrm{min)}$ are proportional to the colour scale, as indicated on the right of the images.

Drastic cerebral

hypometabolism was found in subject $1(A)$,

particularly in the parietooccipital cortex and in the thalamus. In subject 2 (B), parieto-occipital and thalamic hypometabolism was also present. Subject 3 (C) had evident

hypometabolism in the thalamus only, while the pattern of subject 4 (D) was nearly normal, with only mild hypometabolism in the thalamus. There was a correlation between disease evolution and metabolic alterations.

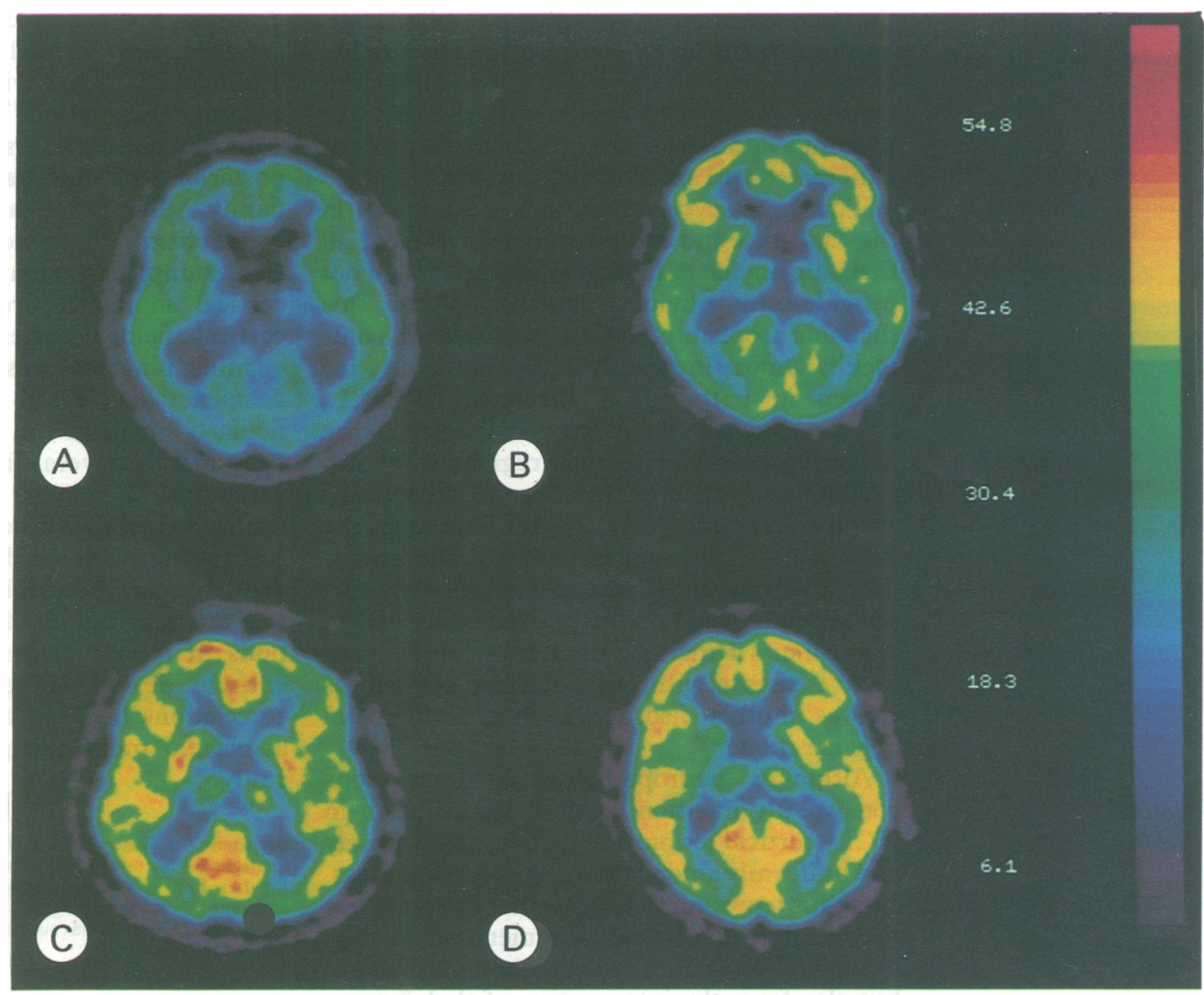

more pronounced in the parieto-occipital cortex and thalamic nuclei. In the thalamus, both relative and absolute hypometabolism (noted by $\star$ in table 2) was found. The pattern in subject 2 was similar, although absolute metabolic rates were significantly decreased ( $>2 \mathrm{SD}$ ) in the parieto-occipital cortex and thalamus only. The study performed in subject 3 demonstrated significant thalamic involvement. In subject 4 , who was less affected clinically, no region was decreased by more than $2 \mathrm{SD}$, although there was evidence of low FDG uptake in thalamic nuclei on visual inspection of metabolic images. PET scans in the four siblings are shown in the figure.

\section{Discussion}

This study of brain glucose metabolism in four siblings with neuronal ceroid-lipofuscinosis (NCL) showed a significant decrease of glucose utilisation in all grey structures, with predominant alterations at the level of the thalamus and in the posterior association cortex. Despite this consistent pattern, the severity of metabolic anomalies varied individually and appeared correlated with clinical signs and disease duration; that is, they were more pronounced in the oldest patient (subject 1), who was also the most affected clinically, and minimal in subject 4 , who had the shortest development period.

The limitations of the autoradiographic PET/FDG method ${ }^{710}$ and its applications to neurological diseases have been discussed elsewhere. ${ }^{611}$ In addition, although CT scan examinations showed some discrete and diffuse atrophy in subjects 1,2 and 3, the data were not corrected for cerebral atrophy. It should be noted, however, that the degree of atrophy was minimal and did not correlate with the regional distribution of metabolic alterations. With these reservations, the rest of the discussion will be based on the premise that the metabolic rates measured reflect the real metabolic state of the tissue. The observation that mean grey glucose utilisation in the four subjects studied was grossly correlated with clinical impairment and with disease duration provides additional support for this assumption.

Some clinical features in our patients were, however, somewhat atypical and deserve comment. Onset in late childhood, intellectual impairment, extrapyramidal features and spasticity were the prominent signs. Light microscopic examination of blood samples revealed vacuolated lymphocytes, and nerve and muscle which are characteristic of the juvenile form of NCL. ${ }^{2}$ Although the absence of visual symptoms is in contrast with the classic descriptions of "juvenile" NCL, ${ }^{12}$ it has been noted in some adult NCL cases, ${ }^{13}$ as well as in some atypical juvenile NCL subjects. ${ }^{13}$ These observations suggest that the patients studied have a variant of NCL closely resembling this latter group. Our metabolic findings may thus not be applicable to all NCL patients.

Nevertheless, our study provides original data on the effects of neuronal ceroid-lipofuscinosis on global and, more interestingly, on regional cerebral function. Inasmuch as NCL is a lipid storage disease which affects widespread regions in the central nervous system ${ }^{13}$ biopsy in subject 1 showed fingerprint profiles 
the decrease in mean grey glucose utilisation is hardly surprising. By contrast, the observation of predominant alterations of glucose metabolism in specific brain regions, particularly the thalamus and posterior cortical areas, was not anticipated and are worth discussing.

The most severe alterations were found in the thalamus and indiscriminately affected all thalamic nuclei. Although available data do not provide any obvious explanation for this thalamic tropism of NCL, the thalamic complex is almost invariably and prominently involved in pathological specimen of NCL, irrespective of their type. ${ }^{3114}$ After the thalamus, posterior cortical regions were also preferentially affected. Intellectual impairment was a salient and early clinical feature in the four subjects and suggests cortical alterations. The involvement of posterior association cortex is reminiscent of the pattern described in Alzheimer's dementia, ${ }^{7}$ the archetype of degenerative disease with cognitive impairment, as well as in other disorders such as corticobasal degeneration. ${ }^{1516}$

Although neuropathological descriptions consistently mention cortical degeneration in NCL, cortical lesions are distributed diffusely and uniformly among the various cortical areas. It is thus tempting to suggest that the posterior predilection of cortical hypometabolism does not solely result from direct pathological insult, but also from the interruption of thalamocortical projections. Indeed, the pulvinar, the largest of the thalamic nuclei, represents the main contribution of the thalamus in PET images and projects heavily to posterior association areas. ${ }^{17}$ The extinction of cortical metabolic activity following subcortical deafferentation has been discussed previously. ${ }^{18}$ In subject 3 and to a lesser extent in subject 4 , thalamic alterations were found in the absence of cortical hypometabolism which further supports that hypothesis. In addition, posterior cortical territories might be more vulnerable than other cortical regions to chronic metabolic disturbances or to a chronic accumulation of toxic metabolites. This idea is supported by our studies of postanoxic syndrome, in which selective hypometabolism of posterior association cortex was also shown. ${ }^{19}$

Like almost all cases of juvenile and adult NCL, the four subjects studied had florid extrapyramidal symptoms, which were associated with relatively preserved glucose utilisation in the striatum. Striatal metabolism is normal or slightly increased in idiopathic Parkinson's disease ${ }^{7}$ but decreased in the case of post-synaptic involvement, as in supranuclear palsy ${ }^{11}$ and striatonigral degeneration. ${ }^{6}$ The relative sparing of striatal metabolism suggests that the extrapyramidal symptoms in our patients are due to nigral rather than striatal lesions, and the involvement of the substantia nigra in NCL has been described in neuropathological studies. ${ }^{131314}$ That the symptoms responded, albeit to a limited extent, to levodopa supports this view. It should be noted, however, that the metabolic pattern found in our subjects does not uniquely distinguish NCL from other akineto-rigid syn- dromes; for example, reminiscent patterns can be seen in early Alzheimer's disease, Parkinson's disease with dementia, and corticobasal degeneration. . $^{16}$

In contrast to the association of thalamic and posterior cortical alterations found in this NCL family, other investigations of inborn errors of metabolism ${ }^{70-23}$ disclosed different patterns. For example, in adenylosuccinase deficiency, cortical anomalies predominated in anterior cortical fields, ${ }^{23}$ whereas in hypoxanthineguanine phosphoribosyl transferase (HPRT) deficiency, decreased FDG uptake was particularly evident in the basal ganglia. ${ }^{20}$ Presumably, several factors (such as regional variations in enzyme activity or in susceptibility to metabolite accumulation) act in concert to determine the distribution of metabolic disturbances. Available observations suggest that the distribution of brain metabolic alterations in inborn errors of metabolism is not entirely devoid of specificity and that the correlations between a given disease and the associated metabolic pattern require further study.

We thank the IBA cyclotron staff, M Cogneau, D Labar and B Georges for isotope preparation, and M Pradella and S Goffinet for their help and encouragement. AG De Volder is a research for their help and encouragement. AG Delgian National Fund for Scientific assistant with the Belgian National Fund for Scientific Research. This

1 Zeman W, Donahue S, Dyken P, Green J. The neuronal ceroid-lipofuscinoses (Batten-Vogt syndrome). In: Vinken PJ, Bruyn GW, eds. Handbook of clinical neurology, Vol 10. Amsterdam, North Holland, 1970;145:588-679.

2 Boustany RMN, Kolodny EH. Neurological progress. The neuronal ceroid lipofuscinoses: a review. Rev Neurol (Paris) 1989;145:105-10.

3 Berkovic SF, Carpenter S, Andermann F, Andermann E, Wolfe LS. Kuf's disease: a critical reappraisal. Brain 1988;111:27-62.

4 Carlier G, Dubru JM. Familial juvenile parkinsonism. Acto Paediatr Belg 1979;32:123-7.

5 Tomé FMS, Brunet P, Fardeau M, Hentati F, Reix J. Familial disorder of the central and peripheral nervous systems with particular cytoplasmic lamellated inclusion in peripheral nerves, muscle satellite cells, and blood capillaries. Acta Neuropath (Berl) 1985;68:209-17.

6 De Volder AG, Francart J, Laterre C, et al. Decreased glucose utilization in the striatum and frontal lobe in probable striatonigral degeneration. Ann Neurol 1989, 26:239-47.

7 Mazziotta JC, Phelps ME. Positron emission tomography studies of the brain. In: Phelps ME, Mazziotta J, Schelbert $\mathrm{H}$, eds. Positron emission tomography and autoradiography: principles and applications for the brain and radiography: principles and applications for the

8 Heiss W-D Hebold I, Klinkhammer $P$, et al. Effect of piracetam on cerebral glucose metabolism in Alzheimer's
disease as measured by positron emission tomography. $J$ disease as measured by positron emission
Cereb Blood Flow Metabol 1988;8:613-7.

9 Kretschmann HJ, Weinrich W. Neuroanatomy and Cranial Computed Tomography. Thieme Verlag, 1986.

10 Gjedde A. Calculation of cerebral glucose phosphorylation from brain uptake of glucose analogs in vivo: a re-examination. Brain Res Rev 1982;4:237-74.

11 Goffinet AM, De Volder AG, Gillain C, et al. Positron tomography demonstrates frontal lobe hypometabolism in progressive supranuclear palsy. Ann Neurol 1989;25: $131-9$.

12 Kohlschütter A, Laabs R, Albani $M$. Juvenile neuronal ceroid lipofuscinosis (JNCL): quantitative description of its clinical variability. Acta Paediatr Scand 1988;77: 867-72.

13 Greenwood RS, Nelson JS. Atypical neuronal ceroidlipofuscinosis. Neurology 1978;28:710-7.

14 Tobo M, Mitsuyama Y, Ikari K, Itoi K. Familial occurrence of adult-type neuronal ceroid-lipofuscinosis. Arch Neurol of adult-type neur

15 Gibb WRG, Luthert PJ, Marsden CD. Corticobasal degeneration. Brain 1989;112:1171-92.

16 Sawle GVS, Brooks DJ, Thompson PD, Marsden CD 
Frackowiak RSJ. Corticobasal degeneration: metabolic and 18F-dopa studies with PET. J Cereb Blood Flow Metabol 1989;9:S338.

17 Carpenter MB, Sutin J. Human neuroanatomy. Baltimore: Williams and Wilkins, 1983 .

18 Baron JC, D'Antona R, Pantano P, et al. Effects of thalamic stroke on energy metabolism of the cerebral cortex. A Positron Tomography study in man. Brain 1986;109: 1243-59.

19 De Volder AG, Goffinet AM, Bol A, Michel C, de Barsy Th, Laterre C. Brain glucose metabolism in postanoxic syndrome: PET Study. Arch Neurol 1990;47:197-204.

20 Palella TD, Hichwa RD, Ehrenkaufer RL, et al. PET scanning in HPRT deficiency. Am J Hum Genet 1985; 37:A70

21 Volkow ND. Patchell L, Kulkarni MV, Reed K, Simmons $M$. Adrenoleukodystrophy: imaging with CT, MRI, and PET. J Nucl Med 1987;28:524-7.

22 Yanai $\mathrm{K}$, Inuma D, Matsuzaxa T, et al. Cerebral glucose utilization in pediatric neurological disorders determined by positron emission tomography. Eur J Nucl Med 1987; 13:292-6.

23 De Volder AG, Jaeken J, Van den Berghe G, et al. Regiona brain glucose utilization in adenylosuccinase-deficient patients measured by positron emission tomography. Pediatr Res 1988;24:238-42. 